\title{
REVISTA
}

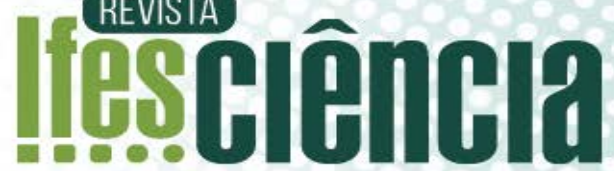

\section{ENTRE INTERDITOS E TRANSGRESSÕES: O EROTISMO NO CONTO “A VIRGEM DOS ESPINHOS”, DE JOÃO GILBERTO NOLL}

\author{
BETWEEN INTERDICTS AND TRANSGRESSIONS: EROTICISM IN THE \\ SHORT STORY “A VIRGEM DOS ESPINHOS”, BY JOÃO GILBERTO NOLL
}

\author{
${ }^{1 *}$ Josiane Brunetti Cani. \\ ${ }^{2}$ Elizabete Gerlânia Caron Sandrini. \\ ${ }^{3}$ Terezinha de Jesus Cani Fagundes. \\ ${ }^{1}$ Instituto Federal de Educação, Ciência e Tecnologia. \\ ${ }^{2}$ Instituto Federal de Educação, Ciência e Tecnologia. \\ ${ }^{3}$ Faculdade Castelo Branco. \\ *Autor correspondente
}

Artigo submetido em 21/11/2020, aceito em 21/12/2020 e publicado em 28/12/2020.

\begin{abstract}
Resumo: Este trabalho analisa a linguagem subversiva inscrita no conto "A virgem dos espinhos", de João Gilberto Noll, com o objetivo de desvendar os interditos e as transgressões relacionadas ao erotismo sob a luz da teoria de Georges Bataille e o signo da diferença dramática, misteriosa e violenta entre o feminino e o masculino, discutida na obra de Francesco Alberoni. A proposta metodológica se baseia na estética da recepção, de Hans Robert Jauss. A contraposição do contínuo e do descontínuo como ponto fundamental da diferença entre os dois gêneros, masculino e feminino, é explicitada no texto. Propõe-se que a linguagem do conto é revestida de elementos literários que conduzem a imaginação do leitor ao mais alto grau de tensão, principalmente em relação às atitudes do sexo masculino.
\end{abstract}

Palavras-chave: Erotismo; transgressão; interdito.

\begin{abstract}
This paper analyzes the subversive language inscribed in the short story "A virgem dos espinhos" (The Virgin of thorns) by João Gilberto Noll, seeking to unveil the interdicts and transgressions related to eroticism by using Georges Bataille's theory, as well as analyzing eroticism under the sign of the dramatic, mysterious and violent difference between the feminine and the masculine, discussed in the work of Francesco Alberoni. The methodological proposal is configured in its reception, based on the "Aesthetics of Reception" by Hans Robert Jauss. The contrast of the continuous and discontinuous as a fundamental difference between the two genders, male and female, is explicit in the text. The proposition that the language throughout the short story is covered with literary elements that lead the reader's imagination to the highest degree of tension, especially regarding male attitudes.
\end{abstract}

Keywords: Eroticism; transgression; interdicted. 


\section{INTRODUÇÃO}

Ao longo da história, a relação entre mulher e erotismo foi um produto cultural desenhado por e para o homem. A representação da mulher, cujos desejos e prazeres foram reprimidos pelo discurso de autoridade masculina, sempre esteve envolta no erotismo. A literatura, sobretudo no século XIX, período em que o erotismo se destaca, reforçou essa reprodução da figura feminina, variando entre o sagrado e o profano.

Entendido como produto da sexualidade, o erotismo aparece na obra de inúmeros autores. Georges Bataille (2013), por exemplo, observa que o erotismo suscita no homem um questionamento da experiência interior. Interditos e transgressões fazem parte do jogo de sedução, e nesse conflito inconciliável, vivido como angústia e dor, o erotismo é vislumbrado.

Octavio Paz (1994, p. 12) considera o erotismo uma metáfora da sexualidade, assim como a poesia é uma metáfora da linguagem. Para o autor, "O erotismo é a sexualidade transfigurada: metáfora. Imaginação é o agente que move $o$ ato erótico e o poético. É a potência que transfigura o sexo em cerimônia e rito e a linguagem em ritmo e metáfora”. Como o erotismo é um fenômeno exclusivamente humano, uma invenção cultural para domar o ato sexual, por meio dele o instinto é ressignificado.

O erotismo está ligado também ao pecado, que "é em sua origem interdito religioso, e o interdito religioso do paganismo é precisamente o sagrado. É sempre ao sentimento de horror inspirado pela coisa interdita que se associam o medo e o pavor de que nem mesmo o homem moderno consegue se livrar face ao que lhe é sagrado" (BATAILLE, 2013, p. 145). Esse pecado nem sempre se apresenta de forma clara e a linha tênue que separa sonho e realidade muitas vezes se dissolve em um sarcástico jogo de aparente supressão dos limites.
Esse fragmento de Bataille sobre o sagrado aponta não só para o pavor à violação, cujo território é muitas vezes invisível, mas também estabelece uma relação paradoxal entre interditos e transgressões. Tal relação é observada na obra heteróclita de outro autor, João Gilberto Noll. Um bom exemplo é seu conto “A virgem dos espinhos”, que será aqui analisado. Nesse conto, Noll aproxima o medo, que intimida, à atração, que conduz ao temor cego.

O erotismo permite ao sujeito colocar sua própria existência em questão, numa experiência de violência interior que se liga a um núcleo de interditos e transgressões dirigido a certas práticas sexuais. Paradoxalmente, interdito e transgressão intimidam e fascinam, embaralhando limites que antes se mostravam intransponíveis e materializando uma nova demarcação. Os lados se mantêm contíguos, em continuidade, embora conservem a oposição. Esse sistema, no entanto, pode se converter em um mundo díspar, resultando no caos e dilacerando o discurso de leis e normas que impõem limites à transgressão.

Sob a luz de Francesco Alberoni e Georges Bataille, dentre outros autores cujos estudos se centram na caracterização do erotismo, o presente artigo analisa o conto "A virgem dos espinhos", de João Gilberto Noll, a fim de desvendar interditos e transgressões relacionadas ao erotismo sob o signo da diferença dramática entre o feminino e o masculino. Para isso, adotamos a estética da recepção de Hans Robert Jauss, destacando a participação do leitor para chegar a uma interpretação do conto.

No referido conto, Noll rompe com técnicas tradicionais, apresentando um objeto estético que desafia a criação literária. Em seu texto, não há apenas conteúdo. Não há palavra isolada. As palavras, somadas umas às outras, implicam a totalidade de um discurso de onde jorram erotismo, paixão, interditos, 
transgressões. Seus personagens angustiados, sem um éthos predeterminado, vivem situações tensas ao longo de toda narrativa.

Nesse cenário, apropriamo-nos, principalmente, das obras de Bataille e Jauss, para analisar a linguagem subversiva inscrita no conto "A virgem dos espinhos", de João Gilberto Noll, com o objetivo de desvendar os interditos e as transgressões relacionadas ao erotismo.

\section{OS ESPINHOS DE UMA VIDA VIRGINAL}

Em 1980, Noll estreia na literatura com $O$ cego e a dançarina. O livro, que reúne 25 contos, rendeu ao autor o prêmio Jabuti, da Câmara Brasileira do Livro, e ficção do ano, do Instituto Nacional do Livro.

"A virgem dos espinhos" faz parte da obra $O$ cego e a dançarina. No conto, um narrador onisciente lança o olhar sobre a vida de uma moça casta de Barra Mansa, devota da Virgem Maria. No início do texto, ao apresentar a personagem, o narrador destaca sua posição social:

\begin{abstract}
Uma virgem de barra mansa? Quem diria é devota da Virgem e está há apenas três meses no Rio de conjugado com mais três companheiras da terra e que amanhã chegará aos 19 anos com a visita do irmão que virá de São Paulo pela Única e que aparecerá diante dela todo aflito pelos espinhos da carne e pelos desabafos da inquisição? (NOLL, 1980, p. 53).
\end{abstract}

A pergunta que inicia a narração destaca a castidade da moça. O tom soa irônico, como se fosse impossível uma virgem naquele lugar, e ainda mais devota da Virgem Maria. A moça, há três meses na cidade do Rio de Janeiro, reside com mais três companheiras da terra natal e trabalha como telefonista em uma empresa chamada NTRKLOPI.
A virgem se envolve com um colega de trabalho, o Saboia, e tem com ele um encontro muito rápido - na verdade, um estupro:

ele abriu o fecho da minha saia e tudo escuro me jogou no sofá e foi por cima de mim e acho que ele já tava pelado e de repente começa a empurrar uma coisa pela minha boca adentro, e a luz voltou aí, e eu com aquilo enfiado na minha boca, me engasgando e ele empurrando, empurrando até que uma coisa quente bateu na minha garganta e ele tirou a coisa dele da minha boca e se atirou pro lado (NOLL, 1980, p. 54-55).

Com escárnio, o narrador delineia a fragilidade da moça e sua incapacidade de resistir ao desejo carnal: "Dói, e ela não nota que sente. Por enquanto vive o seu Calvário” (NOLL, 1980, p. 54). Ainda que momentaneamente, a virgem se rende a seus desejos.

O trágico do conto, além da violência, está na imposição religiosa da pureza e da castidade em contradição com os desejos sexuais, os espinhos da carne. O irmão da personagem, que se considera um responsável pela "Fé Moral do Povo Brasileiro” (NOLL, 1980, p. 56), atormenta a moça e a tortura com repressões religiosas. $\mathrm{O}$ objetivo é que ela se conserve pura como a Virgem Maria Imaculada pelo resto dos dias. Caso contrário, segundo o irmão, a única maneira de manter a fé moral é a morte.

Nessa visão, o prazer é interpretado como um pecado, e a mulher deve aceitar a mortificação de seus desejos, continuando imaculada para preservar sua família, "porque a castidade num homem era um bem e que na mulher era a própria natureza dos céus, e que quem macula a natureza celeste que traz em si é o maior dos criminosos sem perdão de Deus" (NOLL, 1980, p. 57). Com um discurso religioso de castidade, o irmão dita regras e impõe o terror. Em um ato que sugere um incesto, coloca o cano morno de uma arma contra os lábios da irmã - fazendo-a lembrar do mesmo gosto quente sentido na garganta 
quando esteve no apartamento de Saboia -, e a faz jurar se manter casta e santa.

\section{EROTISMO ENTRE DOIS POLOS: INTERDITOS E TRANSGRESSÕES}

Georges Bataille (2013, p. 35) dá sentido ao termo "erotismo" afirmando que dele "é possível dizer que [...] é a aprovação da vida até na morte”. Segundo o autor, embora parta da atividade sexual de reprodução, o erotismo é particular, pois apenas os humanos, diferentemente de outros animais sexuados, fazem de tal contato uma atividade erótica. $\mathrm{O}$ que não significa dizer, no entanto, que toda atividade sexual humana é erótica. Ela assim será sempre que não for simplesmente animal, rudimentar, pois "sexo é animal, só corpo. Erotismo é humano, é interno, é sensível” (BATAILLE, 2013, p. 48). O que o define é uma procura psicológica independente da preocupação com a reprodução da vida, pois “o erotismo é na consciência do homem aquilo que põe nele o ser em questão" (BATAILLE, 2013, p. 56).

Nessa perspectiva, o erotismo é um dos aspectos fundamentais da experiência interior, de dentro para fora, e tem relação com a consciência, atravessada pela dualidade entre a vida e a morte, nos limites da inconsciência. O humano se desvencilhou de sua animalidade inicial "trabalhando, compreendendo que morria e passando da sexualidade livre à sexualidade envergonhada de onde nasceu o erotismo" (BATAILLE, 2013, p. 38). Essas mudanças, ligadas ao plano religioso, determinam o homem.

Paralelamente ao trabalho, fator imprescindível de distinção em relação a outros animais, os humanos "[...] se impuseram restrições conhecidas como interditos. Essas interdições essencialmente - e certamente - recaíram sobre a atitude para com os mortos. É provável que elas tenham tocado ao mesmo tempo - ou pela mesma época - a atividade sexual" (BATAILLE, 2013, p. 35). Portanto, morte e sexualidade são os principais alvos das interdições.

$\mathrm{O}$ interdito, a lei e a norma ligada à morte revelam ao homem que um cadáver é o reflexo de seu destino. A decomposição do corpo é a violência da morte sobre a vida, e as sepulturas, desde os neandertais, são testemunhos do interdito, pois nelas os mortos estão preservados da voracidade dos animais (BATAILLE, 2013, p. 67). Bataille também revela o interdito geral da violência: a proibição do homicídio, explicitando que o objeto fundamental das proibições é a violência, e o mandamento bíblico "não matarás" não pode deixar de ser observado.

Mas qual a relação entre violência e sexualidade? Ora, para Bataille (2013, p. 33), "a sexualidade implica a morte, não somente no sentido de que os recémchegados prolongam e substituem os desaparecidos, mas porque ela faz entrever a vida do ser que se reproduz. Reproduzirse é desaparecer”. Eis a violência elementar da atividade sexual humana, em que o erotismo é a fusão da morte com a vida.

Bataille ainda afirma que a reprodução sexuada provoca certo sentimento de continuidade e descontinuidade, pois não se efetiva "sem uma violação do ser constituído - que se constitui na descontinuidade do outro essencialmente distinto" (BATAILLE, 2013 p. 28). Em síntese, o indivíduo é um ser distinto dos outros. Ele nasce e morre só. Há, portanto, um abismo, uma descontinuidade entre ele e o outro:

Somos seres descontínuos, indivíduos que morrem isoladamente numa aventura ininteligível, mas temos a nostalgia da continuidade perdida. Suportamos mal nossa descontinuidade e ansiamos pela experiência de continuidade pela via daquilo que o amor ou a comunicação torna possível (BATAILLE, 2013 p. 39). 
A ininteligível e desconhecida continuidade do ser é, portanto, "o segredo do erotismo e de que só o erotismo tem o segredo" (BATAILLE, 2013, p. 24). A continuidade está na fusão dos corpos. Essa fusão torna possível diminuir o abismo, mesmo que por pouco tempo, entre o eu e o outro. Assim, o erotismo é a violência que arranca o ser constituído de sua ordem descontínua. No movimento da continuidade, da dissolução dos seres,

a parte masculina tem, em princípio, um papel ativo, enquanto a parte feminina é passiva. É essencialmente a parte passiva, feminina, que é dissolvida enquanto ser constituído. Mas para um parceiro masculino a dissolução da parte passiva só tem um sentido: ela prepara uma fusão onde se misturam dois seres que ao final chegam juntos ao mesmo ponto de dissolução. Toda a concretização erótica tem por princípio uma destruição da estrutura do ser fechado que é, no estado normal, um parceiro do jogo (BATAILLE, 2013 p. 32).

O ser fechado é o ser só, descontínuo, individualidade definida que é. No momento do ato sexual se efetiva o oposto, a continuidade. O indivíduo, em sua nudez, unido ao outro, não está mais fechado, retraído em si mesmo. A figura feminina é a vítima da situação; a masculina, o sacrificador que consuma a destruição da descontinuidade do ser. Percebe-se, com isso, que o erotismo só pode ser concebido na estreita relação do interdito com a transgressão.

Segundo Jacques Lacan (2006), a transgressão é um jogo de inconstância, de mobilidade e de gozo. Nesse jogo, haveria uma conexão conflituosa entre o possível e o impossível, a castração e o gozo, o desejo e a transgressão. Nessa relação, os interditos, mesmo que universais, nem sempre são sacralizados, considerando que são maculados pela paixão, pelo poder sobre o outro. Os limites se mantêm por meio desses interditos, caso contrário a humanidade já teria se reduzido à animalidade, ou uma nova torre de Babel teria se materializado.

No plano metafórico, o interdito adentra o território do erotismo, da violação. Subsiste no homem um desejo de avançar em direção ao outro, em uma escolha consciente que o difere do animal. No desequilíbrio de seu ato, ele não percebe a ameaça à sua vida: "Toda a concretização do erotismo tem por fim atingir o mais íntimo do ser, no ponto em que o coração nos falta. A passagem do estado normal ao de desejo erótico supõe em nós a dissolução relativa do ser constituído na ordem descontínua" (BATAILLE, 2013, p. 14).

A transgressão leva o interdito até o limite de sua existência, conduzindo à sua dissipação, de modo que, a partir desse momento, o homem se reconhece em sua perda. Para Michael Foucault (1963), não há uma relação de oposição entre limite e transgressão, mas um acordo, uma relação em espiral que não se invalida nunca:

O limite e a transgressão devem um
ao outro a densidade de seu ser:
inexistência de um limite que não
poderia absolutamente ser transposto:
vaidade em troca de uma transgressão
que só transporta um limite de ilusão
ou de sombra. Mas terá o limite uma
existência verdadeira fora do gesto
que gloriosamente o atravessa e o
nega? O que seria ele depois e o que
poderia ter sido antes? E a
transgressão não se esgota no
momento em que transpõe o limite,
não permanecendo em nenhum outro
lugar a não ser nesse ponto do
tempo? (FOUCAULT, 1963, p. 32).
erotismo é um processo de violência e de transgressão. Mas “a transgressão difere da 'volta à natureza': ela suspende o interdito sem suprimi-lo. Aí esconde-se o suporte do erotismo e se encontra, ao mesmo tempo, o suporte das religiões" (BATAILLE, 2013, p. 43 - grifo nosso). Não havendo um retorno ao mundo animal, não há destruição total do mundo das regras. Antes, há o acionamento do desejo por meio do interdito. Isso gera o 
fascínio humano pela transgressão. São exatamente essas nuanças que "A virgem dos espinhos” coloca em evidência, dando a ver, entre interditos e transgressões, o erotismo presente na narrativa.

\section{TEORIA DA RECEPÇÃO}

Este trabalho se baseia na estética da recepção de Hans Robert Jauss (1990), que destaca que o leitor não é uma tábula rasa sobre a qual o texto imprime seu sentido. Ao contrário, a partir do texto literário o leitor aciona seu repertório de obras já lidas, ideias e valores, que o auxiliam na interpretação.

A estética da recepção ajuda a dar sentido ao conto "A virgem dos espinhos" por meio de um processo dialógico entre 0 que se sabe e o que se adquire com o conto. O primeiro passo é estabelecer o horizonte progressivo, que vai desde o primeiro contato com o texto até a observação de suas particularidades, como os aspectos sociais e culturais nele presentes. Depois, em um segundo momento, fixa-se a estrutura da obra, ou seja, a construção e a reconstrução dos sentidos por meio de palavras, insinuações e metáforas. Esse jogo, proporcionado pelo autor, toca em temáticas que incomodam e, ao mesmo tempo, possibilita um entrelaçamento entre personagem e leitor, que, no "prazer do texto" (para usar a expressão cara a Roland Barthes), pode chegar a questionar seus próprios preconceitos.

A experiência estética do leitor passa da ficção ao mundo real, à experiência vivida. Por meio dessa experiência, o leitor descobre aspectos ocultos, advindos dos próprios medos, desejos e dúvidas em relação a determinado tema (no caso do conto de Noll, os interditos e transgressões presentes no erotismo). A participação do leitor é, portanto, fundamental.

\section{ANÁLISE DO CONTO}

Em Literatura e Psicanálise, Ruth Silviano Brandão (1996, p. 33), propõe que "a arte literária é talvez o lugar onde o inconsciente se encena de forma privilegiada, pois ela se faz e se constitui no seio mesmo da linguagem”. O que pode surgir quando se tem, de um lado, um conto de Noll, e de outro o olhar de Georges Bataille sobre o erotismo? Certamente, essas são matérias-primas para a corporificação de um texto com imagens alucinantes dos mais profundos desejos. Parte-se, então, para a análise de personagens, mitos e tabus deste conto.

\subsection{A VIRGINDADE}

Podemos começar a análise já pelo título do conto, “A virgem dos espinhos", que constrói uma metáfora por meio da justaposição de "virgem" e "espinhos", ligando os significados convencionais das duas palavras para gerar um sentido que perpassa todo o conto. O espinho, de acordo com Jean Chevalier e Alain Gueerbrant (1994), evoca a ideia de obstáculos, de dificuldades, de defesa exterior e, por conseguinte, de abordagem áspera e desagradável. No contexto do conto, a personagem vive o intenso conflito entre a plenitude da descoberta sexual e as transgressões dos interditos, como fica claro no trecho:

\section{Ela olha a clara névoa da noite e se mortifica como o corpo quando dói. Dói, e ela não notou o que sente. Por enquanto vive o seu Calvário. Os lábios entreabertos, os seios lustrosos para o nada, o colo armado e poderosos vigias - tão cinderela que a gente pensa até que é falso e vão (NOLL, 1980, p. 50-51).}

O erotismo é privilégio do humano, é sexualidade transfigurada no corpo, na pele. E, metafórica ou diretamente, está implícito no trecho um sofrimento estranho, cheio de martírio. A virgem já é "cinderela", arquétipo da sedução feminina. Ela está à espera de um príncipe 
que seja atraído por sua beleza, que a leve, que a salve do calvário em que vive.

No trecho: "[...] foi Saboia e fomos dançar na Barra da Tijuca, depois me convidou para o apartamento dele" (NOLL, 1980, p. 54), observa-se a presença do erotismo. A dança faz parte do jogo de sedução, e, quando esse jogo é vivenciado, a necessidade sexual de Saboia é aflorada. Para provocar desejo sexual no homem, é necessário bem pouco; ele não percebe a delicadeza da sensibilidade feminina.

Como aponta Francesco Alberoni, a palavra "conquista", para o homem, implica 0 ato sexual. Para a mulher, significa romance, envolvimento. A realização do homem acontece no encontro erótico, começa e acaba ali. A da mulher é diferente, ela quer ser lembrada, fazer-se desejada depois do encontro, no dia seguinte, no outro e ainda no outro:

\begin{abstract}
Há uma preferência profunda do feminino para o contínuo e uma preferência profunda do masculino pelo descontínuo. Quando as mulheres dizem que apreciam a ternura, os carinhos e que por isso mesmo os preferem ao ato sexual, não se referem apenas ao aspecto tátil, sensível da experiência. [...] Para a mulher os vários estados emotivos são menos diferenciados que no homem. Para a mulher, a ternura e a doçura combinam com o erotismo (ALBERONI, 2006, p. 2425).
\end{abstract}

Os sonhos elaborados pela mulher se distanciam dos sonhos elaborados pelo homem em um relacionamento amoroso. Isso está presente no trecho do conto de Noll (1980, p. 54): “Ele já tirava aos solavancos a minha calcinha e ia metendo o dedo pelo meu sexo adentro [...] E ele abriu o fecho da minha saia e tudo escuro me jogou no sofá e foi por cima de mim e acho que ele já tava pelado”. Ali, naquele momento, Saboia só vê a mulher como pedaço de carne que satisfaz seus desejos.

Bataille (2013) contempla a distinção entre dois tipos de erotismo: o masculino e o feminino. $\mathrm{O}$ primeiro, segundo 0 autor, relaciona-se à descontinuidade, isto é, está voltado apenas para o prazer sexual imediato, e acontece, preferencialmente, nos homens, visto que estes, em sua maioria, não associam obrigatoriamente a relação sexual aos sentimentos. Já no erotismo feminino, a continuidade erótica, ou seja, a tentativa de união entre o ato sexual e os sentimentos, é aguçada. E esse tipo de erotismo se manifesta, primordialmente, nas mulheres, que tendem a buscar uma relação duradoura.

No trecho “- Só uma vez, juro por Deus e todos os santos! [...] foi Saboia [...] me convidou para o apartamento dele, eu fui acreditando que nada iria acontecer, eu juro!” (NOLL, 1980, p. 54), a virgem transgride uma lei, e a experiência erótica implica a ruptura do cerco da descontinuidade. Essa lei não é anulada pela violação, pois a infração a confirma. A virgem sabe que a descumpriu e, no momento da confissão, confirma a transgressão ao se justificar pelo ato. Todo pecado deixa na alma seus resquícios; o pecado implica sempre uma desordem.

Para Bataille, o interessante do interdito sexual é que ele se revela plenamente na transgressão. No erotismo, prazer e interdito são indissociáveis:

A verdade dos interditos é a chave de nossa atitude humana. Devemos, podemos saber exatamente que os interditos não são impostos de fora. Isto nos aparece na angústia, no momento em que transgredimos o interdito, sobretudo no momento suspenso quando ele ainda atua e que, mesmo assim, cedemos ao impulso a que ele se opunha. Se observamos o interdito, se a ele nos submetemos, não temos mais consciência dele. Mas sentimos no momento da transgressão a angústia sem a qual o interdito não existiria: é a experiência do pecado. A experiência leva à transgressão realizada, à transgressão bem-sucedida que, sustentando o interdito, sustenta-o para dele tirar prazer. A experiência interior do 
mutismo exige de quem a pratica uma sensibilidade bem maior ao desejo que leva a infringir o interdito que à angustia que o funda. É a sensibilidade religiosa, que liga sempre estreitamente o desejo e o medo, o prazer intenso e a angústia (BATAILLE, 2013, p. 26).

O que aponta Bataille pode ser percebido nas reflexões da virgem após o envolvimento com Saboia. Em seus pensamentos, surgem interditos arraigados e, mesmo sem que ninguém a condene, a moça sabe que os transgrediu. Angustiada, tenta justificar seus atos. Sua atitude é a de súplica, uma tentativa de remissão da culpa.

\subsection{O ESTUPRO}

O fragmento "[...] e de repente começa a empurrar uma coisa pela minha boca adentro [...] aquilo enfiado na minha boca, me engasgando e ele empurrando" (NOLL, 1980, p. 54-55) evidencia que o erotismo masculino transgride as regras da ética. O homem não pensa no outro como um fim, e sim como um meio. Simbolicamente, há outra transgressão ética presente no conto:

Foi quando ela viu um embrulho no colo do irmão, um embrulho que ele foi abrindo e mostrando que era um revólver, uma arma pequena, cano curto, é dessas que não fazem barulho, e a arma já era colocada na mão fria dela, olha, pode pegar, olhar, não tem perigo nenhum, pode olhar. O irmão agora a olhava, como momentaneamente saciado. Mas a saciedade não durou muito e ele veio agora se debruçando inteiro, os pingos da boca enorme alvejando a miopia dela, [...] o cano da arma contra os lábios dela, esmagados e sangrados já os dois lábios perdiam as forças e queriam se render enquanto o irmão urrava jura jura, a língua dela já no cano morno (NOLL, 1980, p. 55).

Noll, nesse trecho, mistura o sagrado ao profano. Há, na cena, todo um jogo de sedução. O irmão vê a virgem como imaculada, pura, e ao mesmo tempo a deseja.

As duas cenas podem ser traduzidas como atos de estupro. Saboia transgride as regras da ética quando pratica o ato sexual de forma violenta e despudorada. Observase, então, que o objeto de desejo erótico masculino, a mulher, é vista como meio, ou seja, há uma satisfação carnal individual, egoísta e transgressora. O interdito violado por Saboia se apresenta pelo ponto de vista do narrador extradiegético.

A cena entre a virgem e o irmão também é violenta e erótica. Ela pode ser traduzida como um "estupro incestuoso" em que sexo e violência se sobrepõem por meio da analogia entre o órgão sexual masculino e o revólver, estabelecendo uma forma brutal de submissão total da mulher. A arma representa o poder, a dominação do sexo masculino sobre o feminino. Não foi dada liberdade de escolha à virgem, que sente repugnância, dor, humilhação. A mulher, nos dois casos, é vítima do homem, ficando clara a estreita relação entre interdito e agressão apontada por Bataille (2013).

Analisando as teorias freudianas sobre perversões sexuais, Edgar Pesch (1985, p. 171) afirma:

\footnotetext{
Certas partes do corpo, tais como as mucosas bucais e anais - das quais devemos constatar a importância em todas as práticas -, acabam por ser consideradas como órgãos genitais, sendo tratadas como tal... É o pudor, como precedentemente a repugnância, que constitui a força oposta a estas perversões, mostrandose em certos casos impotente.
}

Nas cenas apresentadas, observa-se que tanto Saboia quanto o irmão da virgem consideram a boca um órgão genital, usado como forma de subjugar a moça e satisfazer os próprios desejos. Tudo aquilo que serve para satisfazer uma necessidade é meio. 
Alberoni trata o estupro como um trauma, porque há um confronto entre o contínuo e o descontínuo. Para o autor, esse ato lacera a vontade. Não há poder de escolha, de decisão, para a mulher estuprada. Para o homem, o estupro é uma fantasia erótica positiva; para a mulher, negativa.

Nas suas fantasias, o homem se imagina passivo. Está sempre pronto a dar-se. A mulher, ao contrário, tem necessidade absoluta de escolher entre o sim e o não. $\mathrm{O}$ direito de não se entregar, de dizer sim ou não é a sua força. Este direito tornou-se constitutivo da sua identidade social. É ela que entregando-se (ou não) decide sobre si mesma, tem um poder de autodeterminação, é uma pessoa humana (ALBERONI, 1990, p. 80).

O irmão se imagina passivo (“estava pronto a dar-se”), pois não usa o membro sexual para violentar a irmã. $\mathrm{O}$ incesto simbólico - encostar o cano da arma contra os lábios da irmã -, era um ato de desprendimento, de doação, mas a virgem não tem a chance de escolher; apenas ouve os urros do irmão a obrigando jurar.

Mas em nenhum momento ela profere as juras. Assim, não se entrega. Eis a força da virgem, revelada. Em seu silêncio diante do agressor, mesmo com a língua ameaçada pelo cano morno, o falo simbólico, ela demonstra seu poder de autodeterminação.

\subsection{O FALO}

No conto de Noll, o jogo erótico se vincula a um vazio que deve ser preenchido pela completude interior. No plano de expressão, observa-se um jogo de palavras que se move em direção ao ato culminante do falo.

Em “Édipo e a paixão”, Hélio Pellegrino (1987, p. 132) recorre à ideia de Lacan segundo a qual o falo é, em última análise, o significado da falta: "Essa falta só pode ser representada através de alguma coisa que a preencha, sendo impossível representar uma falta por outra falta”. E o autor completa: "Um dedo que penetre um cano torna-se significante desse vazio. $\mathrm{O}$ dedo, entretanto, pode vir a significar imaginariamente não o vazio do cano, mas o contrário deste, isto é, sua plenitude" (PELLEGRINO,1987, p. 132).

Na narrativa de Noll, percebe-se a simbologia da falta. O cano da arma é ao mesmo tempo falo, "a coisa que preenche o vazio”, e o próprio vazio, uma vez que é oco. Trata-se, assim, da impossibilidade de representar "uma falta por outra falta". E há, ainda, a boca da virgem, outra falta, preenchida pelo cano da arma, o falo.

Em outra passagem, a imagem fálica volta a aparecer: "ele já tirava aos solavancos a minha calcinha e ia metendo o dedo pelo meu sexo adentro e eu dizendo para, ó meu bem ele respondia, vamos nos divertir um pouquinho, você me ama ou não me ama? Eu te amo ou não te amo? (NOLL, 1980, p. 52). Agora, o dedo simboliza o membro, e o sexo da virgem, a falta, o vazio.

É interessante notar que a falta, nesse contexto, não está restrita somente ao órgão sexual. Ela é a própria essência da virgem. Ela é a falta em si, pois na experiência do desejo falta-lhe o primordial: o erotismo. $\mathrm{O}$ jogo de sedução não existe; há apenas a violência do falo. $\mathrm{O}$ sonho da virgem é que o amor substitua sua falta, o falo. E para tê-lo, é preciso buscá-lo no corpo de Saboia.

Mas o homem está mais preocupado em preencher a própria falta. Saboia é a lógica fálica apenas, enquanto a virgem é o amor. Ele é pulsão de morte, ela é pulsão de vida. Ambas as forças, de vida e de morte, atuam simultaneamente e revelam que a existência do ser humano é ambivalente, e ambiguidade do imaginário se evidencia em sua estreita relação com a pulsão. 


\subsection{EROS E TÂNATOS}

Os instintos de vida e de morte foram observados por Sigmund Freud em Para além do princípio do prazer e chamados de Tânatos (busca da morte) e Eros (luta pela vida). A eles subjaz um ponto fundamental: equilíbrio. Assim, é preciso ficar vigilante para que a morte e a vida convivam harmoniosamente.

Segundo Jean Laplanche e JeanBertrand Pontalis (1992), Eros diz respeito às pulsões responsáveis por tornar a vida mais complexa, aglomerando unidades cada vez maiores e se esforçando por mantê-las. Em oposição a tal complexidade, tem-se Tânatos, que sublinha a pulsão de morte. Esse é o dualismo, de faces complementares, sem o qual a vida não existe. Não se trata, portanto, de oposição, mas de relação e interação. Como afirma Tom Chetwynd (2004, p. 142), "a vida humana desenrolase entre os contrários - amor, nascimento, vida, doença, velhice, morte e decomposição - que nas profundezas do inconsciente se encontram interligados".

A narrativa de Noll evidencia esse equilíbrio, esse entrelaçamento. Por exemplo, quando o irmão, na tentativa de justificar a "pureza" da irmã, considera a morte dos pais uma doação em prol da salvação dos filhos: "não foi o câncer que matou a mãe nem o coração que matou o pai, foram os pecados dos dois filhos que os levaram ao sacrifício" (NOLL, 1980, p. 55). Como propõe Marcuse (1999, p. 97), "se o objetivo básico do instinto não é a terminação da vida, mas da dor - a ausência de tensão - então, paradoxalmente, em termos do instinto, o conflito entre vida e morte é tanto mais reduzido quanto mais a vida se aproximar do estado de gratificação.”

A relação entre Eros e Tânatos pode ser vista ainda na relação entre os dois irmãos: faces da mesma moeda, filhos da mesma mulher. A virgem é Eros, pois é pulsão de vida, autoconservação, símbolo de fertilidade, e se expressa no amor, na continuidade, desejando a atração. Além disso, ela estimula o irmão e Saboia a obter satisfação e desfrutar do prazer. Já o irmão representa Tânatos. É pulsão de morte que se expressa no ódio, na agressividade. Seu instinto é o da repetição, destruição e exclusão. A virgem é o princípio de prazer; o irmão é o princípio de realidade que adia o prazer ao querer impor à moça o que considera "seguro".

Na concepção do irmão, diante de um amor tão grandioso - a morte pela salvação dos filhos - a virgem deveria abnegar todos os prazeres de uma vida desregrada e pecaminosa. Para ver o "Rosto de Deus" e entrar em sua intimidade, deveria se conservar uma "Virgem Maria", imaculada, pois, para o irmão, a castidade da mulher é a própria natureza dos céus. Manchando essa natureza, a virgem se tornaria uma criminosa, sem perdão de Deus.

\section{CONCLUSÃO}

A análise de "A virgem dos espinhos”, de João Gilberto Noll, teve como propósito desvendar no conto interditos e transgressões relacionadas ao erotismo. Para isso, foi usado como suporte metodológico a estética da recepção, de Hans Robert Jauss, que considera as ideias e valores do leitor na interpretação, e as definições de erotismo de Georges Bataille e Francesco Alberoni. A conclusão é a de que a linguagem do conto de Noll conduz a imaginação do leitor ao mais alto grau de tensão, principalmente em relação às atitudes do sexo masculino.

A escrita arrebatadora de Noll deixa entrever erotismo e paixão. Tanto Saboia quanto o irmão da virgem apresentam uma descontinuidade erótico-amorosa em que o prazer sexual se realiza como poder, fúria do corpo e transgressão. Nesses personagens masculinos, o erotismo se mostra avesso à dignidade ética, não considerando a mulher como fim, mas 
apenas como meio, reduzindo tudo ao sexo e ao corpo.

A mulher continua a ser objeto de erotização, meio de desejo para o homem. Há uma ênfase na punição de seus prazeres que impede a relação entre carne, desejo e amor. Assim, a mulher experimenta solidão, inquietude e vazio, sentimentos que a impedem de viver satisfatoriamente suas relações amorosas, sem julgamentos sociais ou culpa pelos próprios desejos. O conto "A virgem dos espinhos" demonstra esses sentimentos e os discursos masculinos enraizados em nossa sociedade.

\section{REFERÊNCIAS}

ALBERONI, Francesco. Erotismo. Milano: Garzanti, 2006.

BARTHES, Roland. O prazer do texto. São Paulo: Perspectiva, 2013.

BATAILLE, Georges. O erotismo. Belo Horizonte: Autêntica, 2013.

BRANDÃO, Ruth Silviano. Literatura e psicanálise. Porto Alegre: Editora da Universidade, 1996.

CHETWYND, Tom. Dicionário dos símbolos. Lisboa: Planeta, 2004.

CHEVALIER, Jean; GHEERBRANT, Alain. Dicionário de símbolos: mitos, sonhos, costumes, gestos, formas, figuras, cores, números. Rio de Janeiro: José Olympio, 1994.

FOUCAULT, Michel. Prefácio à transgressão. In: FOUCAULT, Michel. Estética: literatura e pintura, música e cinema. Rio de Janeiro: Forense Universitária, 1963. (Ditos e Escritos, 3).

JAUSS, Hans Robert. Pour une esthétique de la réception. Paris: Gallimard, 1990.
LACAN, Jacques. Le séminaire de Jacques Lacan, livre XVI, s'un autre à l'autre. Paris: Seuil, 2006.

LAPLANCHE, Jean; PONTALIS, JeanBertrand. Vocabulário da psicanálise. São Paulo: Martins Fontes, 1992.

MARCUSE, Herbert. Eros e civilização: uma interpretação filosófica do pensamento de Freud. Rio de Janeiro: LTC, 1999.

NOLL, João Gilberto. O cego e a dançarina. Rio de Janeiro: Record, 1980.

PAZ, Octavio. A dupla chama: amor e erotismo. São Paulo: Siciliano, 1994.

PELLEGRINO, Hélio. Édipo e a paixão. In: NOVAES, Adauto (org.). Os sentidos da paixão. São Paulo: Companhia das Letras, 1987. p. 307-328.

PESCH, Edgar. Freud. São Paulo: Martins Fontes, 1985. 